\title{
ACRF Instrumentation Status: New, Current, and Future
}

July 2006

James Liljegren

ACRF Instrument Team Coordinator

Work supported by the U.S. Department of Energy, Office of Science, Office of Biological and Environmental Research 


\section{Summary}

The purpose of this report is to provide a concise but comprehensive overview of Atmospheric Radiation Measurement Program Climate Research Facility instrumentation status. The report is divided into four sections: (1) new instrumentation in the process of being acquired and deployed, (2) existing instrumentation and progress on improvements or upgrades, (3) proposed future instrumentation, and (4) Small Business Innovation Research instrument development. New information is highlighted in blue text. 


\section{Contents}

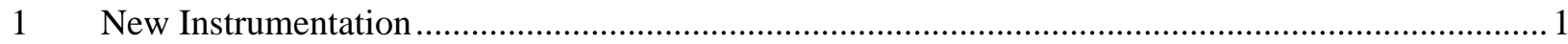

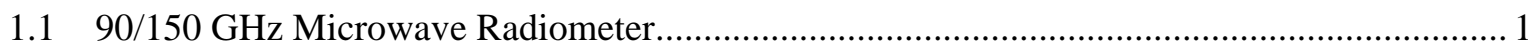

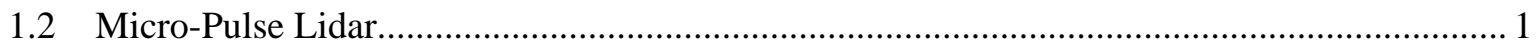

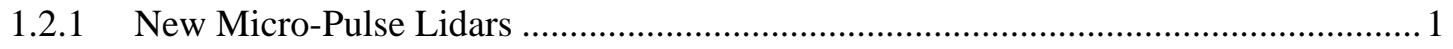

1.2.2 Upgrade Earlier Type-4 Micro-Pulse Lidars.......................................................... 2

1.3 Radar Wind Profiler ................................................................................................... 2

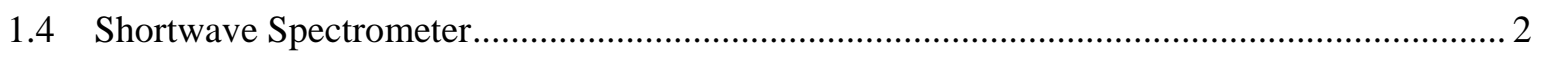

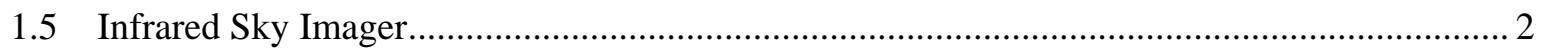

1.6 Cimel Sun Photometer for Atmospheric Radiation Measurement Program Moble Facility..... 3

1.7 Cloud Condensation Nuclei Counter for Southern Great Plains .............................................. 3

1.8 Add Multi-Filter Radiometers to Cessna 206.................................................................... 3

1.9 Hot Plate Total Precipitation Sensor ........................................................................... 4

1.10 Energy Balance Bowen Ratio Station at Darwin .............................................................. 4

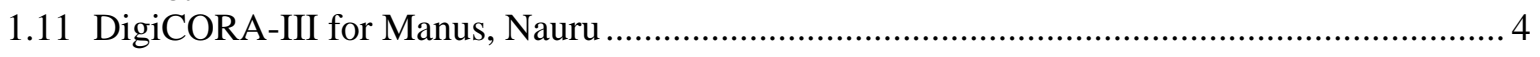

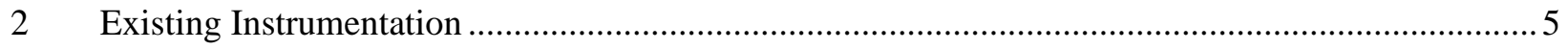

2.1 Atmospherically Emitted Radiance Interferometer ............................................................. 5

2.1.1 Windows and Rapid-Sampling Upgrade ............................................................ 5

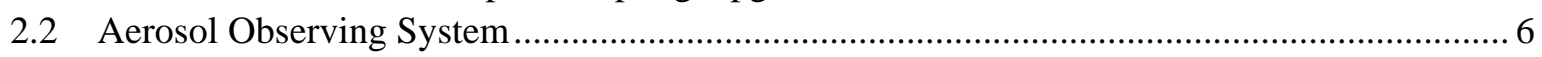

2.2.1 Reconfigure Southern Great Plains Aerosol Observing System ................................ 6

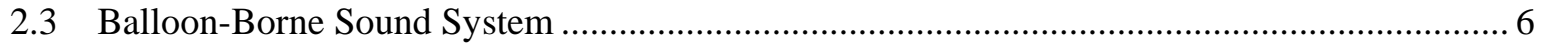

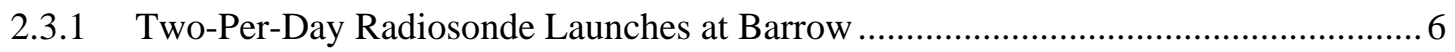

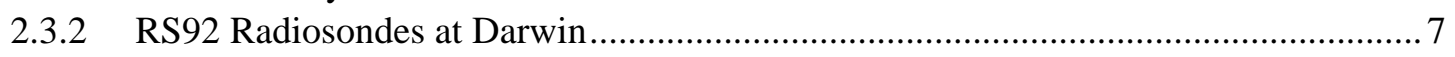

2.3.3 Make Atmospheric Radiation Measurement Program-Barrow Soundings

Available to the Global Telecommunication System ................................................ 7

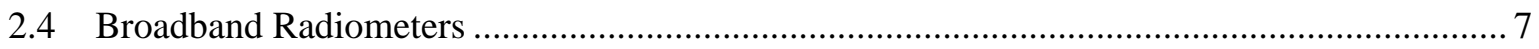

2.4.1 Pyrgeometer Calibration Improvements ........................................................... 7

2.4.2 Radiometer Calibration Facility Data Acquisition System Replacement .................... 8

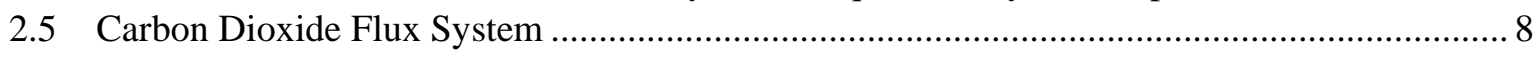

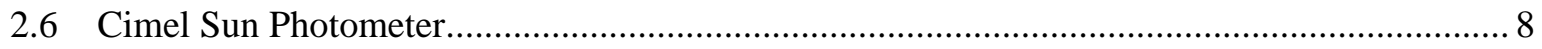

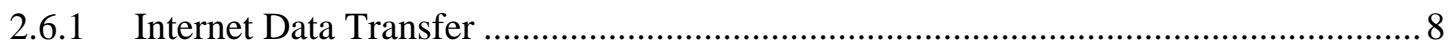

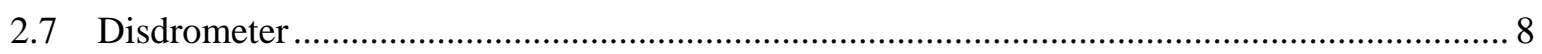

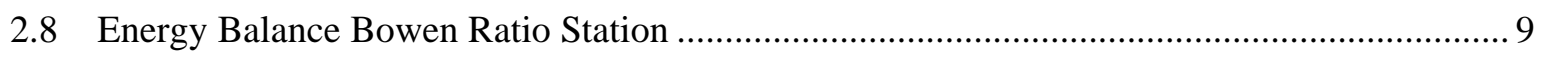

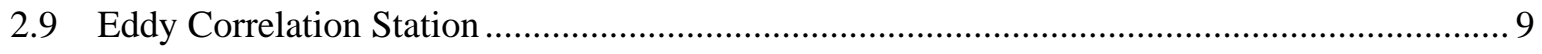

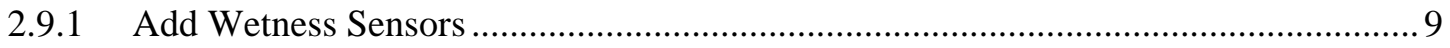

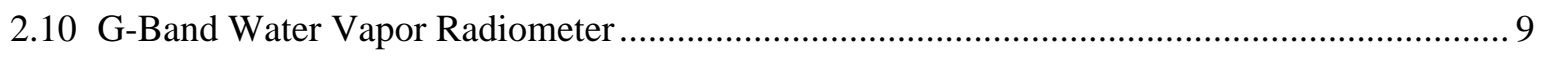

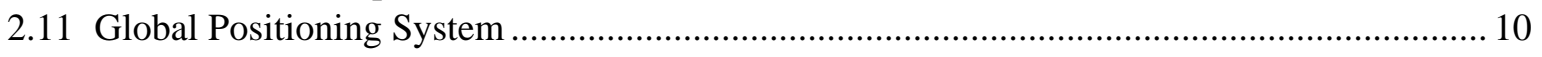

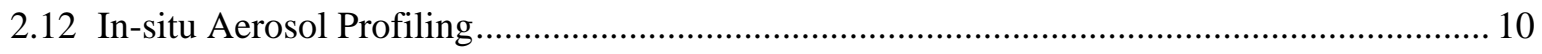

2.12.1 Add Ozone Analyzer to In-situ Aerosol Profiles Suite ............................................ 11

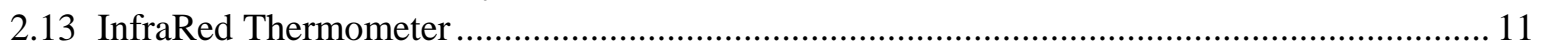

2.14 Multi-Filter Rotating Shadowband Radiometer and Related Systems .................................. 11

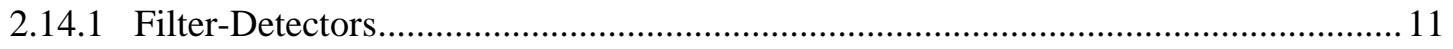


2.14.2 Multi-Filter Rotating Shadowband Radiometer Calibration and Data Processing

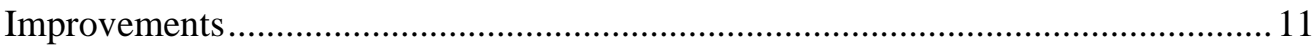

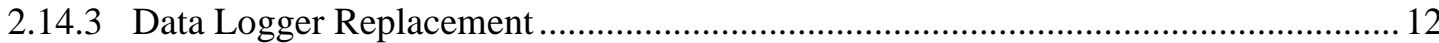

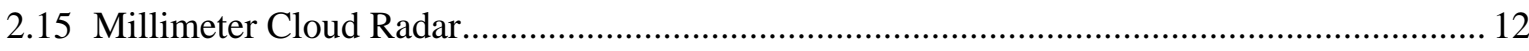

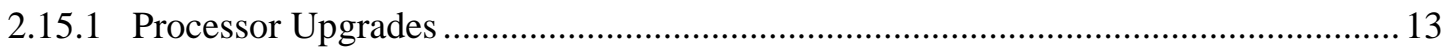

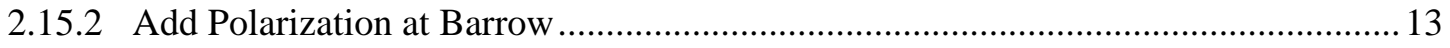

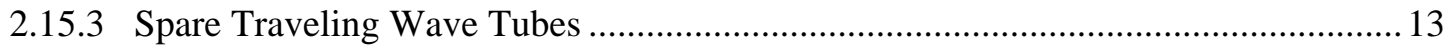

2.15.4 Millimeter Wave Cloud Radar Spectra Processing ................................................. 13

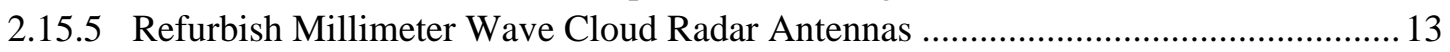

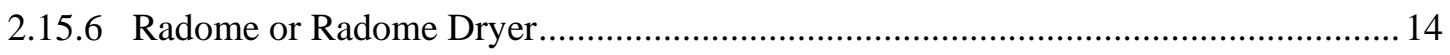

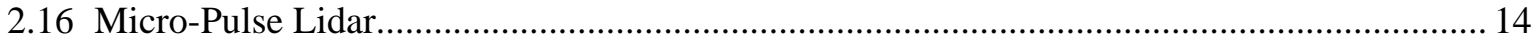

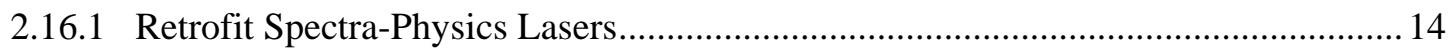

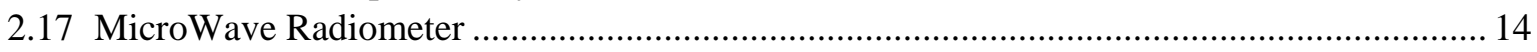

2.17.1 Unify MicroWave Radiometer Connectors......................................................... 14

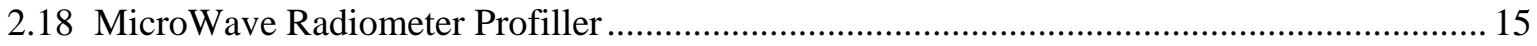

2.18.1 Upgrade MicroWave Radiometer Profiller Software at Barrow …….........................15

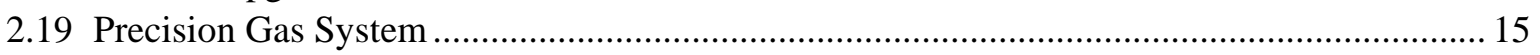

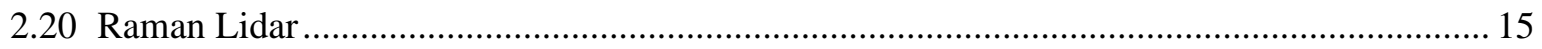

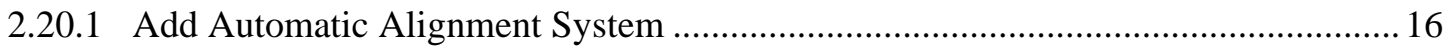

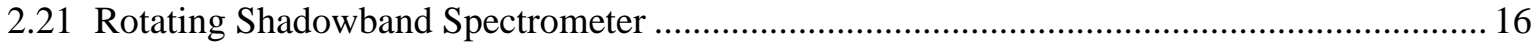

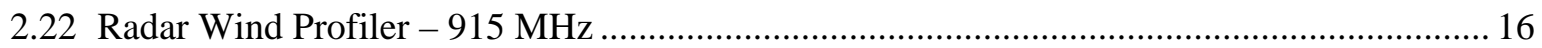

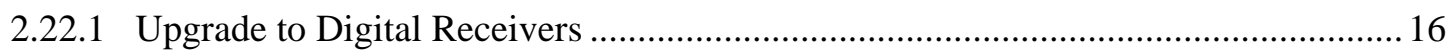

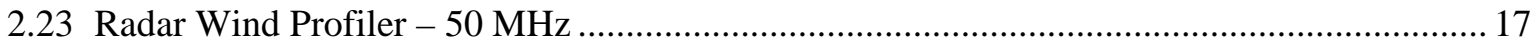

2.24 Soil Water and Temperature System ............................................................................. 17

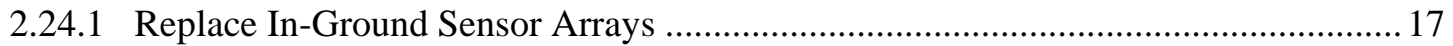

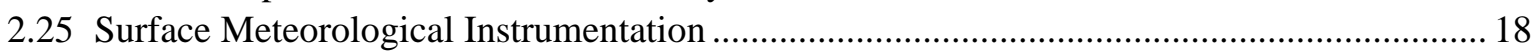

2.25.1 Develop Dynamic Rain Gauge Calibration Facility ............................................... 18

2.25.2 Create Atmospheric Radiation Measurement Program Climate Research Facility Wind Sensor Repair Facility ................................................................................. 18

2.25.3 Develop a Heating System for Barrow Tower Met Aspirator.................................... 18

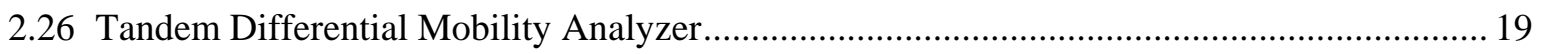

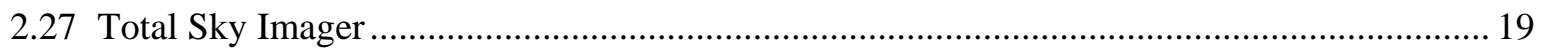

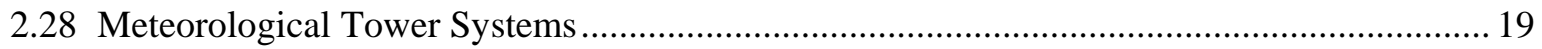

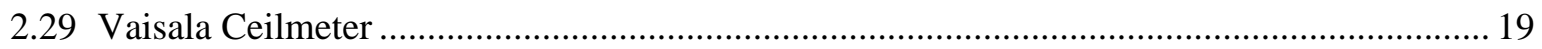

2.30 W-band Atmospheric Radiation Measurement Program Cloud Radar .................................. 19

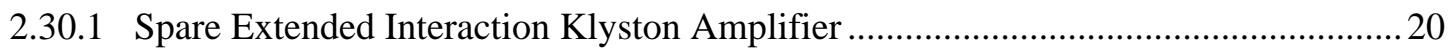

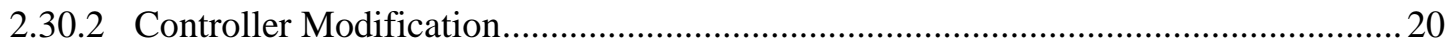

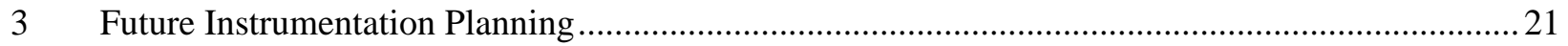

3.1 Atmospheric Radiation Measurement Program Volume-Imaging Array ............................... 21

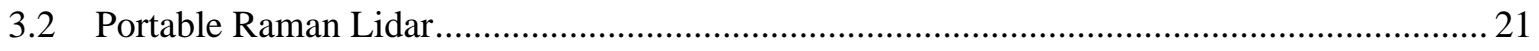

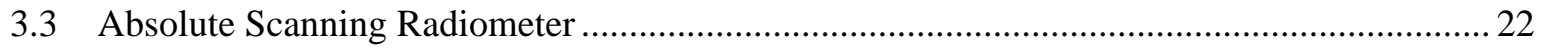

3.4 High-Resolution Oxygen A-Band and Water-Band Spectrometer....................................... 22

3.5 Rotating Shadowband Spectrometer Overhaul .................................................................. 22

3.6 Narrow Field of View Radiometer for Atmospheric Radiatin Measurement Program

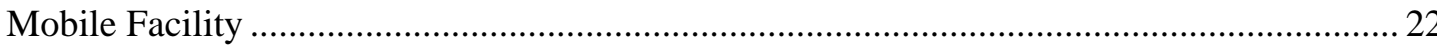


3.7 Add 1.6 $\mu \mathrm{m}$ Channel to Multi-Filter Rotating Shadowband Radiometer and Narrow Field of View.....

3.8 Aerosol Particle Sizing Spectrometer to Replace Optical Particle Counter at Southern

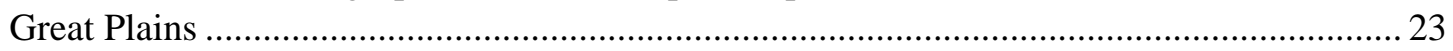

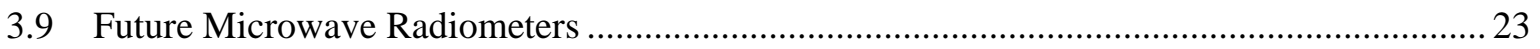

3.10 Modified Muti-Filter Rotating Shadowband Radiometer for Liquid Water Path .................. 23

3.11 Infrared Thermometers for the Southern Great Plains Extended Facility Sites ..................... 24

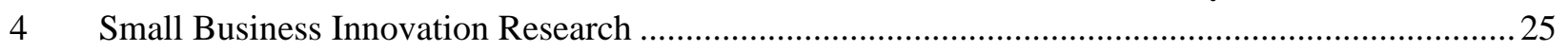

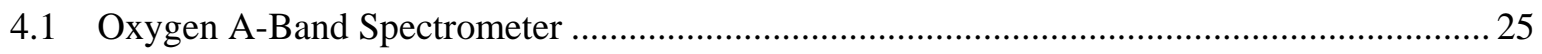

4.2 Eye-Safe Ultraviolet Backscatter Lidar for Detection of Sub-visual Cirrus .......................... 25

4.3 Instrumentation for Remotely Sensing Aerosol Optical Properties -

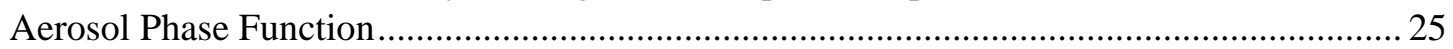

4.4 Unmanned Aerospace Vehicle-Suitable Cloud Radar............................................................ 25

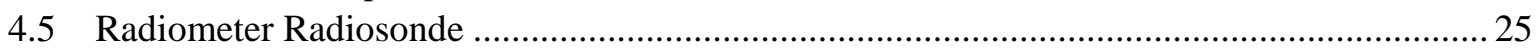

4.6 In-situ Measurement of Cloud Properties with Large Sample Volumes................................. 26 


\section{New Instrumentation}

\section{$1.190 / 150 \mathrm{GHz}$ Microwave Radiometer}

\section{Mentor: Maria Cadeddu, Argonne National Laboratory}

The need for greater sensitivity (and therefore higher frequency) microwave channels to more accurately measure liquid water paths in thin clouds than the current 23.8/31.4 GHz instruments permit has been extensively discussed. Based on a technical evaluation of three proposals submitted for evaluation, Radiometer Physics, GmbH (RPG) (http://www.radiometer-physics.de) has been selected as the supplier with an option to purchase a second instrument (Engineering Change Order [ECO]-00491). RPG has supplied a similar instrument to the University of Munich.

STATUS - The first instrument has been ordered; delivery to Southern Great Plains (SGP) is scheduled for late August. Delivery was delayed to allow the manufacturer to implement a direct detection receiver at $150 \mathrm{GHz}$ similar to the receiver at $90 \mathrm{GHz}$. (This capability was not available at $150 \mathrm{GHz}$ at the time the order was placed.) Following acceptance testing at SGP, the instrument will be deployed to the North Slope of Alaska (NSA)-Barrow. Once the first instrument is accepted a second instrument will be ordered. The second instrument will be deployed with the Atmospheric Radiation Measurement (ARM) Program Mobile Facility (AMF) to Germany in 2007.

\subsection{Micro-Pulse Lidar}

Mentor: Albert Mendoza, Pacific Northwest National Laboratory; Rich Coulter, Argonne National Laboratory

\subsubsection{New Micro-Pulse Lidars}

Four new Micro-Pulse Lidars (MPLs) (type-4b-YAG) have been ordered (ECO-00577). Combined with the upgrades described below, this will permit a new (or like new) MPL and an older type MPL to be deployed at each site (SGP-Central Facility [CF], NSA-Barrow, Tropical Western Pacific [TWP]-Darwin, TWP-Manus, TWP-Nauru, and AMF). The new type-4b models will use a Photonics YAG laser with a shorter pulse width to achieve a minimum detection height of $\sim 90 \mathrm{~m}$ rather than the 150-300 m detection height of the YLF laser in the earlier type-4b models. The new systems will all have the ability to measure depolarization.

STATUS - Two of the four new MPLs have been delivered to SGP. In May Sigma Space provided comprehensive on-site training in the installation, set up, operation, maintenance, problem diagnosis, and repair of the system. Acceptance testing was carried out; the instruments met all specifications. An intermittent problem with the interaction between the software and the A/D converter has been observed. A new version of the software that is expected to resolve the problem will be delivered with the next two new systems, which are scheduled for delivery to SGP in late July. These will be sent to TWP (Darwin) and AMF (Niamey). Training for the Bureau of Meteorology (BoM) technicians is scheduled for 23-25 August at Darwin, Australia. 


\subsubsection{Upgrade Earlier Type-4 Micro-Pulse Lidars}

Because the LiteCycles laser is no longer supported, the type-4 acquired in 2004 will be upgraded to a $4 \mathrm{~b}$, which involves engineering modifications in addition to replacing the laser; the 4b-YLF models acquired in 2005 will be upgraded to 4b-YAG by replacing the laser only.

STATUS - All three systems have been returned to Sigma Space for upgrade. They will be upgraded by Sigma Space to be identical to the new type-4b-YAG instruments. The upgraded MPLs are scheduled to be delivered by August.

\subsection{Radar Wind Profiler}

Mentor: Rich Coulter, Argonne National Laboratory

A refurbished 4-panel 915 MHz Radar Wind Profiler (RWP) has been rented from Vaisala for the 2006 AMF deployment in Niamey (ECO-00513).

STATUS - The $915 \mathrm{MHz}$ RWP was installed at Niamey during the last week in March. Its antenna was overturned in an intense windstorm in mid-June, which damaged one of the data cables. Replacing the cable and interface boards restored the system to operation by early July.

A 4-panel $1290 \mathrm{MHz}$ RWP has been ordered from Vaisala for the 2007 AMF deployment in Germany. An operating frequency of $1290 \mathrm{MHz}$ was selected to match EU and other global frequency allocations for boundary layer radar profilers. Delivery is scheduled for September 2006 (ECO-00513).

STATUS - The Federal Aviation Adminstration (FAA) denied a request for a license to operate the new RWP at the SGP for testing prior to the AMF deployment to Germany in April 2007.

\subsection{Shortwave Spectrometer}

Mentor: John Pommier, National Aeronautics and Space Administration - Ames Laboratory

This instrument replaces the analytical spectral devices spectrometer that was removed from service in 2003 after repeated hardware problems. The new SWS will provide zenith spectral radiances in the range of 350-1700 $\mathrm{nm}$ at a maximum rate of $10 \mathrm{~Hz}$. A LabSphere integrating sphere has been purchased to permit frequent calibrations to be performed at SGP (ECO-00428).

STATUS - The SWS was deployed at the SGP in April. The data are available from the ARM Archive.

\subsection{Infrared Sky Imager}

Mentor: Vic Morris, Pacific Northwest National Laboratory

An IR sky imager from Blue Sky Imaging (http://www.aas.org/career/bluesky.html) was deployed at SGP in September 2005 to provide nighttime cloud cover measurements (ECO-00429). 
STATUS - Problems with water infiltration of the imager necessitated its return to the manufacturer for repair/revision in October 2005. The unit was returned to SGP in late June. Currently, advice and documentation from the manufacturer is being sought prior to reinstallation.

\subsection{Cimel Sun Photometer for Atmospheric Radiation Measurement Program Moble Facility}

The Aerosol Working Group endorsed the deployment of a Cimel sun photometer (CSPHOT) with the AMF. Although ARM owns 4 CSPHOT instruments, one of which is a spare that could be used for this purpose, Brent Holben (National Aeronautics and Space Adminstration [NASA] Aerosol Robotic Network [AERONET] principal investigator) has indicated that he would prefer ARM continue to use the spare Cimel to ensure the uninterrupted operation of our three field units. A new instrument will be purchased to support the AMF so that we still have a spare for calibration swaps. AERONET has agreed to support the new instrument (ECO-00560).

STATUS - To deploy a Cimel to Niamey sooner than the anticipated July delivery of the new unit, the spare Cimel that had been deployed on Nauru was sent to AERONET for calibration in late March. This instrument has been sent to Niamey and is currently being installed. Data will be processed by AERONET (station name: Niamey). The new Cimel was delivered to SGP in early July.

\subsection{Cloud Condensation Nuclei Counter for Southern Great Plains}

Mentor: John Ogren and Anne Jefferson, National Oceanic and Atmospheric Administration/Earth System Research Laboratory/Global Monitoring Division

A Cloud Condensation Nuclei (CCN) counter has been included in the aerosol observing system (AOS) for the AMF. A CCN counter for SGP is planned for Fiscal Year (FY) 2006. See http://www.dropletmeasurement.com/(ECO-00565).

STATUS - The SGP unit has been delivered and will be installed in September by Anne Jefferson. To accommodate the new CCN counter, John Ogren plans to reconfigure the SGP AOS early in FY 2007 to match the configuration of the AMF AOS, and to update the SGP AOS data acquisition system to match that of the AMF AOS.

\subsection{Add Multi-Filter Radiometers to Cessna 206 (In-situ Aerosol Profiling aircraft)}

Currently, spectral albedo measurements are only possible at the SGP central facility using downward facing Multi-Filter Radiometers (MFR) on the 25-m level of the 60-m tower over a wheat field, and on a 10-m tower over the adjoining pasture. By adding a MFR to the Cessna 206 used for the In-situ Aerosol Profile (IAP), routine measurements of surface spectral albedo could be acquired over a broader area around the SGP central facility (ECO-00584).

STATUS - Moved up to 2006 from 2007 because millimeter wave cloud radar (MMCR) processor upgrades for SGP and NSA have been deferred to 2007. Pat Sheridan is working with multi-filter 
rotating shadowband radiometer (MFRSR) mentors Gary Hodges and John Schmelzer to choose a suitable location on the aircraft to mount the sensor head and to integrate the data acquisition.

\title{
1.9 Hot Plate Total Precipitation Sensor
}

\author{
Mentor: Mark Ivey, Sandia National Laboratory
}

This is a new sensor developed by Roy Rasmussen at National Center for Atmospheric Research and commercialized by Yankee Environmental Systems. It offers the promise of accurate snowfall measurements without the need of an expensive World Meteorological Organization (WMO)-standard double fence inter-comparison reference shield or troublesome WMO-standard Geonor weighing precipitation gauge. It also offers the promise of handling under-catchment due to winds. One Total Precipitation Sensor (TPS) was acquired for deployment at Barrow in November 2005. The instrument will be deployed in close proximity to a double fence inter-comparison reference and Geonor gauge deployed by the National Oceanic and Atmospheric Adminstration (NOAA) Climate Reference Network (CRN). If the first sensor compares well with the CRN measurements, a second TPS could be acquired for mounting on the 40-m tower at Barrow to discriminate between blowing and falling snow. CRN is planning to deploy a station at Atqasuk, so installation of the TPS at Atqasuk is not presently envisioned.

STATUS - In June the TPS was mounted on the Great White Shelter at Barrow for testing. Collection and ingest modules are being developed. Once the collection and ingest is completed the instrument will be installed on a piling near the Barrow CRN station. Budget cuts at NOAA have caused CRN to defer plans to install a station at Atqasuk; therefore acquisition of a second TPS for Atqasuk may be desirable if the first unit proves successful at Barrow.

\subsection{Energy Balance Bowen Ratio Station at Darwin}

The Cloud Parameterization and Modeling Working Group recommended deploying an Energy Balance Bowen Ratio (EBBR) station at the TWP-Darwin site in 2006 to provide measurements of the surface energy balance (ECO-00562).

STATUS - This has been cancelled based on a discussion at the 2006 Science Team meeting between the CPMWG and the TWP Site Scientist Team. An alternative would be to support Nigel Tapper and colleagues who have deployed EBBR stations and other instrumentation at more representative sites in the region around Darwin.

\subsection{DigiCORA-III for Manus, Nauru}

Mentor: Barry Lesht, Argonne National Laboratory

The digiCORA is the ground station for the Vaisala balloon borne sounding system. In FY 2003-2004 new digiCORA-III systems were acquired and deployed at SGP-CF, NSA-Barrow, and AMF as the primary ground station for those sites. For reliability and compatibility reasons it is necessary to replace the digiCORA-II systems at Manus and Nauru with the new digiCORA-III systems.

STATUS - Ordered. 


\section{Existing Instrumentation}

This section describes the current status of the existing instrumentation, including any upgrades planned or in progress. The information is abstracted primarily from the Instrument Mentor Monthly Summary reports (available from the instrument web pages) and from ECO status updates.

\subsection{Atmospherically Emitted Radiance Interferometer}

Mentor: Jack Demirgian, Argonne National Laboratory

At the beginning of June there were seven Atmospherically Emitted Radiance Interferometers (AERIs) operating, with one spare at the University of Wisconsin Space Science and Engineering Center (SSEC). On June 26 a laser failure in the NSA-S01 AERI necessitated reconfiguring the NSA-C1 AERI as a Windows XP-based system and removing the NSA-S01 system for repair. Four AERIs are currently still OS/2-based systems producing data every 8 minutes: SGP CF (SGP-C1), Nauru (TWP-C2), Darwin (TWP-C3), and AMF-Niamey. The system at Barrow (NSA-C1) was OS/2-based until June 26 but in rapid sampling mode with samples collected approximately every 25 seconds. The single AERI remaining at Barrow (NSA-S01) and at the SGP central facility (SGP-E14) are Windows XP-based and in 10-second rapid sampling mode.

The Barrow (NSA-C1) AERI in the "Great White Shelter" was 50\% noisier than the other Barrow (NSAS01) AERI located in the adjacent steel sea container. This is currently being attributed to radiofrequency interference. To test this, in June two SSEC technicians traveled to Barrow to swap these instruments. Unfortunately the 10-year old laser in the NSA-S01 system would not restart after the move. The interferometer from the NSA-C1 AERI was mated with the NSA-S01 Windows XP computer to permit rapid sampling and re-installed in the sea container. The interferometer from the NSA-S01 AERI was shipped to Bomem for repair. The noise was observed to be somewhat reduced. Repairs to the failed interferometer are expected to take months.

\subsubsection{Windows and Rapid-Sampling Upgrade}

Migration of the AERI software from OS/2 Warp to Windows XP and related computer hardware modernization to enable rapid sampling of the IR spectrum at 10-s intervals was begun in FY 2004 (ECO00286). In FY 2005, 2 AERI systems were upgraded and installed at NSA-Barrow and SGP-CF. In 2006 the AERI systems at Darwin, Nauru, and the second system at Barrow will be upgraded in the field. The Barrow system will be upgraded first, compared with the previously upgraded system at Barrow that was completely recalibrated at SSEC. The AERI deployed with the AMF will be upgraded in 2007, following the completion of the Niamey deployment. The spare AERI at SSEC will not be converted to a MAERI. Instead it will be upgraded to rapid sampling and Windows then deployed with the AMF in 2007. Ralph Dedecker recommends fully recalibrating it after the upgrade.

STATUS - The Barrow (NSA-C1) system was to be the first AERI to be upgraded this year. As described above this instrument developed a problem believed to be due to RF interference. A second AERI at Barrow (NSA-S01) had been upgraded to rapid sampling and Windows XP last year does not exhibit this problem. In the course of swapping these two systems, the laser in the NSA-S01 system 
failed. The interferometer from the NSA-C1 system was mated with the Windows XP-based computer from the NSA-S01 system; the NSA-S01 interferometer was shipped to Bomem for repairs.

\subsection{Aerosol Observing System}

Mentor: John Ogren and Anne Jefferson, National Oceanic and Atmospheric Administration/Earth System Research Laboratory/Global Monitoring Division

AMF - The harsh conditions in Niger have taken their toll on the AOS instrumentation. The CCN counter has been powered down: the relative humidity in the CCN counter was unusually high suggesting water may have condensed in it; background checks (signal with filtered air) suggest dirty optics; the signal is near the detection limit, which could be due to dirty optics or a malfunctioning valve. Both nepholometers and the optical particle counter also need to be overhauled and the optics cleaned. Anne Jefferson is planning to travel to Niamey in August to service the AOS.

\subsubsection{Reconfigure Southern Great Plains Aerosol Observing System}

The AOS at SGP will be reconfigured to have similar components and data acquisition system as the aerosol systems for AMF, NSA, and the IAP aircraft measurements over the SGP ECO-00569).

STATUS - This work is scheduled for fall 2006 (FY 2007).

\subsection{Balloon-Borne Sound System}

\section{Mentor: Barry Lesht, Argonne National Laboratory}

Over $90 \%$ of the soundings done at NSA, SGP, and TWP/C1 (Manus) exceed the height and pressure targets of $20 \mathrm{~km}$ and $50 \mathrm{hPa}$. Ascent rates were generally within acceptable range (4-6 m/s). There is an inverse relationship between ascent rate and altitude at termination. As a result, the NIM (Niamey) and TWP/C2 (Nauru) soundings, which generally had the highest ascent rates, tended to terminate earlier and at lower altitudes than the other ARM soundings.

In June, Barry Lesht and Mike Ritsche traveled to Barrow to upgrade the digiCORA-III ground station for TCP/IP communication (ECO-00466), to upgrade its software (BCR-1219) and the firmware of the ground-check system used to validate the radiosondes prior to launch. They also set up a spare digiCORA-II at the ARM Duplex as a backup to be used for radiosonde launches in the event drifting snow prevents access to the ARM site. Finally, they trained the local sonde launch personnel in the use of the global positioning system (GPS)-capable RS92 sondes and ground check equipment.

\subsubsection{Two-Per-Day Radiosonde Launches at Barrow}

STATUS - Two-per-day radiosonde launches (0600 and 1800 Greenwich Mean Time) began on 1 April. These initially used the RS90 sondes on-hand that only report pressure, temperature, and relative humidity to reduce the current sonde inventory. Use of RS92 sondes with GPS wind-finding capability that also report wind speed and direction began in May. 


\subsubsection{RS92 Radiosondes at Darwin}

STATUS - The Australian BoM began using RS92 (instead of RS80) radiosondes at Darwin with the 23:16 Universal Time Coordinates launch on 18 January 2006.

\subsubsection{Make Atmospheric Radiation Measurement Program-Barrow Soundings Available to the Global Telecommunication System}

STATUS - Barry is working with NOAA to obtain a WMO station identifier for the ARM Climate Research Facility (ACRF) Barrow site. Having a permanent station ID for Barrow will facilitate transmittal of Barrow soundings to the Global Telecommunication System.

\subsection{Broadband Radiometers (SIRS, SKYRAD, GNDRAD, BRS)}

Mentor: Tom Stoffel, National Renewable Energy Laboratory

\subsubsection{Pyrgeometer Calibration Improvements}

Tom Stoffel and Ibrahim Reda have initiated an investigation into the source of the bias in the ACRF pyrgeometer blackbody calibration system. Once the source of the bias is determined and corrected a careful validation of the system and a comparison of pyrgreometers calibrated with this and other systems will be conducted (ECO-00559).

STATUS - The original Eppley calibrations were re-installed in the pyrgeometers (Eppley Precision Infrared Radiometers, or precision infrared radiometers [PIRs]) at NSA and TWP in December, prior to the start of TWP-ICE. SGP followed in January. In January 6 PIRs were returned to Eppley for recalibration. According to Tom Stoffel 5 of the 6 exhibited minimal changes in their responsivity. (BCR-1162) The source of the calibration bias appears to be due to a $1.5^{\circ}-2.0^{\circ} \mathrm{C}$ temperature gradient in the blackbody that develops below $-20^{\circ} \mathrm{C}$ when the viscosity of the silicone oil coolant becomes too great to provide proper mixing. National Renewable Energy Laboratory (NREL) has redesigned and is testing the fluid dispersion manifolds surrounding the blackbody to reduce thermal gradients. In February Ibrahim Reda began exploring alternative outdoor characterization of pyrgeometers using the sky as a calibration source in conjunction with a reference pyrgeometer traceable to the World Infrared Standard Group. In March Joe Michalsky, Ells Dutton, and Ibrahim Reda exchanged groups of pyrgeometers recently calibrated by PMOD/WRC (Groebner) to confirm data analysis methods, and continued evaluating results from three PIRs with 3 dome thermistors, three PIRs with a single dome thermistor, and a CG4 in a round-robin involving NREL and NOAA blackbodies and outdoor characterizations.

Paper accepted for publication: Reda, et al. 2006: “Calibrating Pyrgeometers Independent from a Reference to Measure the Atmospheric Longwave Radiation.” Journal of Atmospheric \& Solar Terrestrial Physics.

Tom Stoffel attended the 9th BSRN Science Review and Workshop, Lindenberg, Germany with poster presentation on pyrgeometer calibrations for the ARM Program. 


\subsubsection{Radiometer Calibration Facility Data Acquisition System Replacement (deferred to FY 2007)}

The data acquisition system in the Radiometer Calibratin Facility (RCF) used for annual Broadband Outdoor Radiometer Calibration (BORCAL) activities is over ten years old and needs to be updated. NREL has recently replaced their BORCAL data acquisition system using internal funds. The SGP system should be a duplicate of the NREL system for software compatibility and performance assurance.

\subsection{Carbon Dioxide Flux System}

Mentor: Marc Fischer, Lawrence Berkeley National Laboratory

The Carbon Dioxide Flux System instruments at 4, 25, and $60 \mathrm{~m}$ on the SGP-CF tower are operating nominally. In late May all instruments were calibrated. In June the soil and supporting meteorology sensors for the $4 \mathrm{~m}$ system were moved for farm operations in the tower field. During this period, the eddy flux systems continued to collect valid data.

\subsection{Cimel Sun Photometer}

Mentor: None (external data provided by National Aeronautic and Space Administration Aerosol Robotic Network)

CSPHOT systems at SGP, NSA, and TWP (Nauru) are operating nominally.

In May an ARM-owned Cimel was deployed at NSA (Barrow) to replace the AERONET-owned unit that had been deployed at Barrow through last year. AERONET refurbished and calibrated this instrument and upgraded it to add heaters for Arctic conditions at no expense to ARM. AERONET also loaned ARM a Sutron satellite transmitter until Internet data transfer is established (see below).

\subsubsection{Internet Data Transfer}

The transfer of CSPHOT data from the Cimel instrument to AERONET using geostationary operational environmental satellite or Meteosat will be replaced with an Internet data transfer to improve reliability of the transfer, to permit ACRF personnel to monitor the transfer, and to allow the raw data to be acquired, ingested, and archived for use by ARM Science Team members (ECO-00555).

STATUS - Tim Grove (SGP) has obtained the necessary software from AERONET to acquire the data from the Cimel and has successfully tested it on the new Cimel delivered to SGP. Tim is working with NSA Site Operations personnel to implement this capability at Barrow.

\subsection{Disdrometer}

Mentor: Mary Jane Bartholomew, Brookhaven National Laboratory

The need for accurate measurements of rain drop size distribution at TWP-Darwin and SGP-CF was assigned a high priority by the Cloud Properties working group. NOAA Environmental Technology 
Laboratory has had good experience with the Joss-Waldvogel impact disdrometers offered by Distromet (http://www.distromet.com/) (ECO-00488). The first disdrometer and its associated tipping bucket rain gauge were deployed at Darwin in December 2005, prior to the start of TWP-ICE. The second disdrometer and rain gauge were deployed at SGP in April. Collection and ingest are installed and operational; data are available from the ARM Archive. Dead time corrections are being prepared to account for multiple raindrops that occur too close in time to be distinguished from a single large drop.

TWP (Darwin) - In July the disdrometer was removed from service and sent to the manufacturer for annual calibration.

\subsection{Energy Balance Bowen Ratio Station}

\section{Mentor: David Cook, Argonne National Laboratory}

All EBBR stations are operating nominally. Occasional problems with the automatic exchange mechanism and in-ground sensors are noted. Observed biases between the EBBR net radiometer and Solar Infrared Station radiometer suite are attributed in part to the known calibration bias in the PIRs.

\subsection{Eddy Correlation Station}

\section{Mentor: David Cook, Argonne National Laboratory}

SGP - All Eddy Correlation Station (ECOR) stations except at SGP/E1 and SGP/E14 are operating nominally. In late May the station at SGP/E1 was removed and shipped to Argonne for evaluation of the serial communication problems between the Infrared Gas Analyzer and the sonic anemometer.

AMF - The $\mathrm{CO}_{2}$ concentration and flux data from the AMF ECOR are periodically affected by aircraft operations at the adjacent Niamey airport.

\subsubsection{Add Wetness Sensors}

Periods of dew, frost, and precipitation often cause data from the $\mathrm{CO}_{2} / \mathrm{H}_{2} \mathrm{O}$ sensor and sonic anemometer to be incorrect. Adding a wetness indication would provide the data user with a more reliable source of information concerning this condition (ECO-00536).

STATUS - Wetness sensors have been ordered.

\subsection{G-Band (183.3 GHz) Water Vapor Radiometer}

\section{Mentor: Maria Cadeddu, Argonne National Laboratory}

In May the G-Band Water Vapor Radiometer (GVR) was returned to ProSensing for upgrades based on the evaluation of its first year of deployment. These included improving the receiver stability, hardening the radiometer against radio-frequency interference from the nearby distant early warning Line radar, making the serial communication more robust, and eliminating unnecessary connectors in the data cables. 
The GVR will be returned to Barrow in late July. Development of an ingest module is underway to permit GVR data to be available from the ARM Archive (ECO-00591).

\subsection{Global Positioning System (SuomiNet)}

Mentor: None (external data provided by SuomiNet/COSMIC)

SGP - All 15 SuomiNet GPS stations and their associated meteorological sensors are operating nominally.

TWP - Communication problems between the met sensors and the GPS receiver at Darwin developed in March but were not identified until May, when they were quickly corrected. The temperature/relative humidity sensor associated with the Manus Island system failed in July 2005 but was not discovered until May 2006. The sensor will be replaced on the next service visit to Manus Island. Procedures for routinely examining the data from the SuomiNet systems were developed and implemented in response to these problems.

NSA (Barrow) - (System belongs to the University of Alaska at Fairbanks (UAF) and is installed at NOAA/CMDL site.) The temperature/relative humidity probe associated with the Barrow system failed in August 2005. In June, following discussions with UAF personnel, NSA personnel replaced the failed GPS met system with a spare from the SGP and returned the failed system to UAF for repair.

NSA (Atqasuk) - In June University Navstar Consortium personnel installed a GPS receiver at Atqasuk for geodetic purposes. However, if ARM contributes a GPS meteorological system to connect to the receiver, this station could be incorporated into SuomiNet and provide precipitable water vapor data.

\subsection{In-situ Aerosol Profiling}

Mentor: John Ogren and Betsy Andrews, National Oceanic and Atmospheric Administration/Earth System Research Laboratory/Global Monitoring Division

The new Cessna 206 that replaced the old Cessna 172 began flights over the SGP in September 2005 using the aerosol equipment package from the 172. In February FAA approval was obtained for the new equipment racks and IAP flights resumed over SGP with the new equipment on March 2, 2006. The three main improvements to the equipment are (1) the inlet does not have a 1-um impactor upstream of the instruments for better comparison with remote sensing instruments at the surface and in orbit; (2) a 3-wavelength PSAP which, together with the total sky imager (TSI) nephelometer ( 450, 550 and $700 \mathrm{~nm}$ ), will allow for calculation of spectral single scattering albedo; (3) three Radiance Research nephelometers measuring scattering at three relative humidities ( $<40 \%, 64 \%, 85 \%)$ downstream of a 1 um impactor for better characterization of the hygroscopic growth of the particles.

In May the Lawrence Berkeley National Laboratory's Continuous Carbon Analyzer was installed on the Cessna 206 and became operational. In June there were 7 IAP flights, bringing the total number of flights over the SGP to 632. 


\subsubsection{Add Ozone Analyzer to In-situ Aerosol Profiles Suite}

STATUS - In June an ozone analyzer was added to the IAP instrument suite by NOAA/GMD at no cost to ACRF (ECO-00589). This instrument is currently being used by GMD to measure vertical profiles of ozone 2-3 times per month at 8 sites in the U.S. on aircraft operated by the North American Carbon Project. It is also included in the NOAA Airborne Aerosol Observatory Cessna 206 that has recently begun obtaining aerosol and trace gas profiles 2-3 times weekly in east-central Illinois.

\subsection{InfraRed Thermometer}

Mentor: Vic Morris, Pacific Northwest National Laboratory

InfraRed Thermometers (IRTs) have been deployed at 12 SGP extended facilities (ECO-345), operating at $5 \mathrm{~Hz}$ sampling rate. IRTs are also part of the SKYRAD and GNDRAD systems at TWP, NSA, and AMF. These are currently sampled at $0.5 \mathrm{~Hz}$. Plans to increase the sampling rate of the SKYRAD IRTs to $5 \mathrm{~Hz}$ are in progress (ECO-00368).

\subsection{Multi-Filter Rotating Shadowband Radiometer and Related Systems (MFR, GNDMFR, NIMFR)}

Mentor: Gary Hodges, National Oceanic and Atmospheric Administration/Earth System Research Laboratory/Global Monitoring Division; John Schmelzer, Pacific Northwest National Laboratory

SGP - 8 of 22 Extended Facilities do not have operational MFRSRs due to a shortage of sparesensor heads. Several others are operating with at least one failed channel. In May the normal incidence multifilter radiometer (NIMFR) was returned to service after repair. NSA - MFRSR operating nominally. At Atqasuk the $940 \mathrm{~nm}$ channel of the NIMFR has failed. TWP - Operating nominally. AMF - Operating nominally.

\subsubsection{Filter-Detectors}

ACRF has 50 multi-filter radiometers deployed in a variety of configurations including the MFRSR, the downward-facing MFR, and the NIMFR. The 6 narrow band $(10 \mathrm{~nm})$ filter-detectors in almost all of these sensors have degraded over time and are in urgent need of replacement. Perkin-Elmer is producing custom-designed and custom-built filter-detector assemblies to meet ACRF specifications.

STATUS - Ten sets of filter-detectors will be delivered in late July and the remaining balance in late August or early September.

\subsubsection{Multi-Filter Rotating Shadowband Radiometer Calibration and Data Processing Improvements}

Problems with the calibration and data processing of the MFRSRs were revealed during the ALIVE campaign (ECO-00571). 
STATUS - Joe Michalsky convened a meeting at Pacific Northwest National Laboratory during the last week of January to discuss the calibration issues and develop a plan to address them. Participants included Gary Hodges, Patrick Disterhoft, Mikhail Alexandrov, John Schmelzer, Jim Barnard, Annette Koontz, Peter Armstrong, and Jim Liljegren. The details of the meeting and plan are given in ECO-00571. Nighttime measurements will be collected from the existing MFRSRs to derive an offset correction. New calibration processing will be implemented based on the consensus procedures developed during the meeting. Old data will be reprocessed to apply the offset corrections and the new calibration and processing procedures. Collection and ingest development are proceeding but have been delayed by the need to accommodate both the current proprietary data loggers and the new Campbell Scientific data loggers.

\subsubsection{Data Logger Replacement}

The proprietary data loggers supplied with the MFRSRs and related instruments are to be replaced with Campbell Scientific CR10X data loggers. Because CR10X data loggers are widely used by ACRF, this will permit them to be more easily maintained. It will also permit modifications to the operation of the instruments and data acquisition to be easily implemented (ECO-00350).

STATUS - New model CR1000 data loggers will be used instead of the CR10X. A collection module has been developed to acquire the data from the CR1000. The data logger programming is still being finalized as is the ingest module. A deployment plan is being developed.

\subsection{Millimeter Cloud Radar}

Mentor: Kevin Widener, Pacific Northwest National Laboratory; Karen Johnson, Brookhaven National Laboratory

SGP/C1 - nominal operation.

NSA/C1 - nominal operation.

TWP/C1 (Manus) - While at Manus to install the new processor, Kevin Widener observed the sensitivity shift phenomenon that has been affecting this system. It appears to be caused by the pulse controller. It may be possible to replace the pulse controller following the processor upgrade at Nauru.

TWP/C2 (Nauru) - Radio Frequency (RF) attenuator needs recalibration.

TWP/C3 (Darwin) - The RF attenuator at Darwin has a significantly different calibration than the other MMCRs. The consequence of this possible incorrect calibration is that the reflectivity measurements of the Darwin MMCR are off by $10 \mathrm{dBz}$ based on a comparison of Contoured Frequency by Altitude Diagram plots between Manus and Darwin. Kevin will attempt to recalibrate this before his Nauru trip or will work with Rex Pearson to do so. 


\subsubsection{Processor Upgrades}

The MMCRs at SGP-central facility and NSA-Barrow have been upgraded with the (now obsolete) C40 digital signal processor. The new PIRAQ-III processors from Vaisala have been received for the three MMCRs at TWP, and the installation at Darwin completed in early November 2005. The installations at Manus and Nauru will be done after TWP-ICE. The systems at SGP and NSA need to be upgraded from the C40 processors in 2006. A spare PIRAQ-III board set will be acquired in FY 2007 (ECO-00283).

STATUS - Kevin Widener and Rex Pearson installed the new processor at Manus in June. Kevin will install the new processor at Nauru in August. The PIRAQ-III processors for NSA and SGP have been deferred to 2007 to allow time for the spectral image problems with the processors to be resolved. A spare PIRAQ-III processor has been ordered this year.

\subsubsection{Add Polarization at Barrow}

Acquisition and installation of an orthomode transducer is necessary to add polarization to the MMCR at Barrow. Modifications to the PIRAQ-III processor will be necessary to support the polarization capability. Polarization will be added during the summer of 2006 using the C40 processor. The modifications to the PIRAQ processor will be completed prior to the upgrade of the SGP system, and then installed at Barrow later in 2006 (ECO-00552).

STATUS - Delivery of the orthomode transducer is scheduled for 30 June 2006.

\subsubsection{Spare Traveling Wave Tubes}

New traveling wave tubes (TWT) will be ordered to replace the TWTs originally delivered with the MMCRs, which are well beyond their rated lifetime and are beginning to fail (ECO-00425).

STATUS - Delivery of the first TWT is scheduled for 31 July 2006.

\subsubsection{Millimeter Wave Cloud Radar Spectra Processing}

Spectra files produced by the upgraded MMCRs (C40 or PIRAQ-III processors) range from 8 to 15 Gigabytes per day. Algorithms for eliminating clear-sky periods and compressing the files need to be developed and implemented locally (ECO-00391).

STATUS - The algorithms have been developed and tested. Implementation is underway. Karen Johnson is developing a test plan to validate each installation before data are irretrievably discarded.

\subsubsection{Refurbish Millimeter Wave Cloud Radar Antennas}

Beginning in 2007, over a three-year period the MMCR antennas will be refurbished and characterized on an antenna range (ECO-00391). 


\subsubsection{Radome or Radome Dryer}

The detrimental effect on the data of standing water on the current fabric radome has prompted the pursuit of a more satisfactory solution. Unfortunately discussions with potential suppliers have not been fruitful. This task, initiated in 2003, is currently on hold (EC-00275).

STATUS - Still on hold.

\subsection{Micro-Pulse Lidar}

Mentor: Albert Mendoza, Pacific Northwest National Laboratory

All MPL systems are working well with the exception of the system at Nauru. The Nauru MPL is exhibiting a low signal-to-noise ratio. The system is currently double pulsing: a condition where the laser produces two pulses per trigger instead of one, which can be identified by an artifact in the backscatter data at $0.25 \mathrm{~km}$.

The energy monitor of the AMF MPL often detects electronic noise during the nighttime. This is not affecting the backscatter measurements.

\subsubsection{Retrofit Spectra-Physics Lasers}

The type- 1 and type- 2 units use Spectra-Physics lasers that are no longer supported (except for the AMF unit, which uses a LiteCycles laser that is no longer supported). ARM has one spare Spectra-Physics laser head. Four old Spectra-Physics laser supplies have been retrofitted by Sigma Space to use Coherent F-System laser diode modules and two remain to be retrofitted (ECO-00362).

STATUS - The remaining two laser supplies are currently in the field (at NSA and SGP). Once the new type-4b-YAG MPLs are deployed to NSA and SGP, these systems will be removed and upgraded. The Coherent F-System laser diode module is an interim measure until the new MPLs are deployed. Double pulsing of the lasers retrofitted with Coherent supplies has been occasionally observed in several MPL systems in the field. This produces an artifact at $0.25 \mathrm{~km}$.

\subsection{MicroWave Radiometer}

Mentor: Maria Cadeddu, Argonne National Laboratory

All microwave radiometers are operating nominally except at the AMF site in Niamey. RFI in Niamey causes frequent spikes in the MicroWave Radiometer (MWR) data. Also, the high air temperatures at Niamey (greater than $40^{\circ} \mathrm{C}$ ) cause the MWR to overheat, which corrupts the calibration.

\subsubsection{Unify MicroWave Radiometer Connectors}

The Impulse connectors on the 3 MWRs at the TWP sites make it difficult to substitute a spare MWR in case of a failure, as occurred in Darwin prior to TWP-ICE due to a lightning strike. Accordingly, the Impulse connectors are being replaced with the standard connectors used on all other MWRs. 
STATUS - The MWR that was damaged in a lightning strike at Darwin has been repaired and its connectors replaced. This MWR has been shipped to Nauru will be swapped with the MWR there in August, which will then be sent to the manufacturer for connector replacement. After the connectors are replaced the MWR will then be swapped with the unit at Manus in October.

\subsection{MicroWave Radiometer Profiller}

Mentor: Maria Cadeddu, Argonne National Laboratory

NSA (Barrow) - In June the MicroWave Radiometer Profiller (MWRP) failed to restart after a planned power outage. The instrument has been returned to the manufacturer for diagnosis and repair.

AMF (Niamey) - RFI at Niamey causes frequent spikes in the MWRP data. A shift in the calibration of some channels occurred following an unplanned power outage in June. The IRT on the MWRP is biased high relative to the SKYRAD IRT by $5-7^{\circ} \mathrm{C}$.

\subsubsection{Upgrade MicroWave Radiometer Profiller Software at Barrow}

While the MWRP from Barrow is being repaired, it will also be upgraded to the latest version of the manufacturer's software (and hardware) to match the MWRP at Niamey. This will permit faster operation of the radiometer. The format of the raw data files from both instruments will then be the same (ECO-00592).

\subsection{Precision Gas $\left(\mathrm{CO}_{2}\right)$ System}

Mentor: Margaret Torn, Lawrence Berkeley National Laboratory

Nothing to report.

\subsection{Raman Lidar}

Mentor: Diana Petty, Pacific Northwest National Laboratory

The Raman lidar is operating nominally (98\% uptime) with the exception of increased frequency of "bad alignment” events.

In June Diana Petty traveled to Madison, Wisconsin to work with Dave Turner on the algorithm that merges the analog and photon counting measurements and other Raman lidar-related topics. Diana submitted extended abstracts for her 2006 ARM Science Team posters: "ARM program Raman Lidar at SGP: New measurement capabilities" and "Cirrus extinction and lidar ratio from Raman Lidar measurements at the ARM SGP site.”

Zhien Wang (University of Wyoming) has been working on algorithms for temperature and liquid water content profiling. 


\subsubsection{Add Automatic Alignment System}

Due to small thermal gradients in the laser and the lidar enclosure, the alignment of laser beam in the detectors' field-of-view (FOV) changes with time, which can affect the data quality, sometimes substantially. To address this operationally, the laser beam is swept through the detectors' FOV using a pico-motor controlled steering mirror to find the optimal location. This "alignment tweak" is scheduled to occur every 3 hours. Accounting for the potentially 3-hourly changes in alignments is the single largest uncertainty in the data processing codes. It affects all measurements, but the aerosol extinction measurements and the temperature profiles seem to be the most sensitive. Licel has recently developed a new product that permits the alignment of the lidar to be actively maintained (ECO-00586).

STATUS - The Licel alignment sensor has been ordered. September delivery is anticipated.

\subsection{Rotating Shadowband Spectrometer}

\section{Mentor: Peter Kiedron, State University of New York at Albany}

The Rotating Shadowband Spectrometer (RSS) is operating nominally. Field calibrations are nominal. Automatic processing of calibration data is under development by Peter Kiedron and Jim Schlemmer.

Peter Kiedron contributed to an ARM Newsletter article about the RSS. See http://www.arm.gov/acrf/updates061506.stm

A new RSS was recently delivered to NREL. Peter is working with Tom Stoffel to evaluate its performance.

\subsection{Radar Wind Profiler - $915 \mathrm{MHz}$}

Mentor: Rich Coulter, Argonne National Laboratory

SGP - Currently, the systems at the central facility (C1), Beaumont (I1) and Medicine Lodge (I2) are operating nominally, though the RASS data at Medicine Lodge are "reflected" at large range gates. The phase shifter at the central facility was replaced in February and the interface power supply was repaired. The Meeker (I3) system is currently out of service due to a failed interface unit between the amplifier and phase shifter. No further attempts to repair the I3 interface will be made because this will be replaced as part of the receiver upgrade (below).

NSA - System crashes frequently.

\subsubsection{Upgrade to Digital Receivers}

The four $915 \mathrm{MHz}$ RWPs at the SGP are now 9-13 years old and are exhibiting increasingly frequent, strange, and expensive-to-repair failures. This may pose problems for CLASIC, scheduled in 2007. Due to the age of these systems, parts are increasingly difficult to obtain (Vaisala no longer has exact replacements for some items; the available parts must be modified for use in our systems). Vaisala offers an upgrade for these systems that will replace the present interface, receiver and computer (including DSP 
board) with new components and will include the latest version of LAPXM, the operating system. The systems at SGP/CF and SGP/I3 will be upgraded first, prior to CLASIC. The systems at SGP/I2 and SGP/I3 will be upgraded in 2007. The RWP at NSA will also be upgraded to be consistent with the SGP systems (ECO-00567).

STATUS - Two PIRAQ-III digital receiver upgrades have been ordered for a 30 August delivery.

\title{
2.23 Radar Wind Profiler - $50 \mathrm{MHz}$
}

Mentor: Rich Coulter, Argonne National Laboratory

In January the $50 \mathrm{MHz}$ RWP at the SGP ceased transmitting. The transmitter was returned to ATRAD in Australia for diagnosis and repair. After reinstalling the transmitter the output power was still zero. The power tube was replaced but the output power is still zero. Vaisala will loan SGP test equipment to help diagnose the problem. The system is currently out of service.

\subsection{Soil Water and Temperature System}

\author{
Mentor: John Harris, University of Oklahoma
}

John Harris has replaced Don Bond as the Soil Water and Temperature Systems (SWATS) instrument mentor.

\subsubsection{Replace In-Ground Sensor Arrays}

The in-ground sensors for the SWATS deployed at all 22 SGP Extended Facilities (EFs) are arranged in two redundant vertical arrays so that if/when a sensor fails, there is a redundant sensor at the same level. This is necessary because disturbing the soil to replace a failed sensor adversely affects the measurements for 6-12 months afterward depending on soil type. At this time 8 of the 22 SWATS installations have at least one failed sensor, and 5 sites have 2 or more failed sensors. These sensors cannot be replaced without disturbing the soil and invalidating the measurements at all levels. To address this problem, new redundant sensor arrays will be installed at the SGP EF sites. These will be installed in a phased manner: 5 sites per year over the next 4 years beginning in 2005 with the sites having multiple failed sensors given highest priority. After the soil recovers from the installation process in 6-12 months, the new sensor array will be connected to the existing SWATS data acquisition system in place of the old sensor array (ECO00493).

STATUS - Installation of the replacement sensor arrays at the first five sites began in late March and was completed in May. New sensors for the next five sites to be replaced in the fall have been ordered. 


\subsection{Surface Meteorological Instrumentation (SMET, SMOS, SURTHREF, THWAPS, MET, ORG, PWS)}

Mentor: Mike Ritsche, Argonne National Laboratory

SGP (Surface Meteorological Observing Station [SMOS]) - All systems operating nominally. TWP (SMET, ORG) - Lower wind sensor at Manus indicates low, may have a bad bearing.ORG at Darwin reports $0.1 \mathrm{~mm} / \mathrm{hr}$ constantly. BoM tipping bucket rain gauges at Manus and Nauru will be connected to the SMET systems. A tipping bucket rain gauge will be added at Darwin. NSA (METTWR) - Icing continues to be a problem on the wind direction sensors.

AMF (MET, ORG) - In May the ORG was not reporting rainfall and was replaced. In June the ORG appeared to be underreporting relative to the PWS and non-ACRF tipping bucket rain gauge.

In June Mike Ritsche traveled to Barrow to train NSA personnel on met sensor calibration checks and change outs, and on the correct procedures for datalogger swaps for the SKYRAD and GNDRAD systems. While at NSA Mike assisted Barry Lesht with balloon borne sounding system upgrades.

\subsubsection{Develop Dynamic Rain Gauge Calibration Facility}

The tipping bucket rain gauges at the 15 SGP/EF sites with SMOS are currently calibrated using only a "static" calibration: a measured volume of water is poured into the gauge and the number of bucket tips is checked to ensure they correspond. In reality, as the rain rate increases and the bucket tips more frequently some rain is not collected. The purpose of the dynamic calibration is to determine the correction factor as a function of rain rate to account for this behavior (ECO-00495).

STATUS - All necessary components have been received. Software development by the University of Iowa is nearing completion.

\subsubsection{Create Atmospheric Radiation Measurement Program Climate Research Facility Wind Sensor Repair Facility}

Rather than return ACRF wind sensors to the manufacturer for repair, it is cost effective and far quicker to perform the repairs and calibrations on-site. Repair facilities will be established at the SGP central facility and the TWP Darwin site (ECO-00561).

STATUS - All necessary components have been received. Testing and repair procedures are being developed.

\subsubsection{Develop a Heating System for Barrow Tower Met Aspirator}

Ice develops on the aspirator inlets for the temperature and relative humidity sensors, which clog and affect the data quality. Install heaters to prevent the build-up of ice without adversely affecting the measurements. 
STATUS - This has not been successful in preventing icing. Replacing the sensors with sonic sensors is being considered.

\subsection{Tandem Differential Mobility Analyzer}

Mentor: Don Collins, Texas A\&M University

Data from the Tandem Differential Mobility Analyzer (TDMA) are currently acquired and processed by Don Collins. Processed data are then delivered to ACRF on a monthly basis and stored in the IOP area of the Archive as "beta-data." An ingest is being developed to produce netcdf files for inclusion in the main Archive (ECO-587).

\subsection{Total Sky Imager}

Mentor: Vic Morris, Pacific Northwest National Laboratory

SGP - Operating nominally. Birds occasionally perch on system, affecting the imagery. Deterrents have been installed. TWP - In mid-May the TSI controller board at Darwin failed. Both spares are being repaired; two additional spares are being fabricated. NSA - Operating nominally. AMF - Sky cover fraction is biased high due to high atmospheric aerosol loading.

\subsection{Meteorological Tower Systems}

Mentor: David Cook, Argonne National Laboratory

60-m tower at SGP C1 (central facility) - nominal operation. 21-m tower at SGP E21 (Okmulgee) nominal operation.40-m tower at NSA C1 (Barrow) - problems due to ice formation on temperature/ humiditysensors and on the wind direction vanes continue. Replacement of these sensors with sonicanemometers is being considered (ECO-00081).

\subsection{Vaisala Ceilmeter}

Mentor: Vic Morris, Pacific Northwest National Laboratory

SGP - Operating nominally. TWP (Darwin) - Sensitivity is reduced, possibly due to a failing receiver.

\subsection{W-band (95 GHz) Atmospheric Radiation Measurement Program Cloud Radar}

\section{Mentor: Kevin Widener, Pacific Northwest National Laboratory}

In March the AMF W-band ARM Cloud Radar (WACR) was successfully deployed at Niamey. In April the SGP WACR was returned to service. In May the pulse repetition frequency at Niamey was changed from $10 \mathrm{kHz}$ to $8333 \mathrm{~Hz}$ to increase the maximum unambiguous range from $15 \mathrm{~km}$ to $18 \mathrm{~km}$. This also decreases the maximum unambiguous Doppler velocity from $8 \mathrm{~m} / \mathrm{s}$ to $6.6 \mathrm{~m} / \mathrm{s}$. 


\subsubsection{Spare Extended Interaction Klyston Amplifier}

A spare Extended Interaction Klyston Amplifier (power tube) and modulator will be purchased to support the two WACRs deployed at SGP and AMF.

STATUS - Ordered.

\subsubsection{Controller Modification}

To permit using a corner reflector for calibration, the WACR at SGP will be returned to ProSensing in late summer for controller firmware modification and RF switch characterization (ECO-00585). 


\section{Future Instrumentation Planning}

In this section instrumentation that have been proposed for future acquisition and discussed by the Science Team Working Groups - but not yet approved for purchase - are presented along with any status information.

\subsection{Atmospheric Radiation Measurement Program Volume-Imaging Array}

The ARM Volume-Imaging Array (AVA) is a proposed radar system to be deployed at the ARM SGP site to address the ARM program's need of mapping 3D cloud and precipitation structures at short to medium ranges (i.e., 20-75 km). The AVA system will provide time-resolved 3D precipitation fields, domain-averaged rainfall rate, cloud coverage throughout a volume, cloud-top heights, hydrometeor phase information (using polarization), horizontal and vertical variability of clouds and precipitation, and low-level convergence and divergence using dual-Doppler techniques. Principal elements of the AVA proposal prepared by Pavlos Kolias include:

Three networked scanning radars arranged in a triangle with 20-30 km legs: one operating at $35 \mathrm{GHz}$ (same 8.6-mm wavelength as the MMCR) and capable of scanning the vertical region probed by the current MMCR, and two radars operating at $9.4 \mathrm{GHz}$ (3.2-cm wavelength, so-called "X-band"). All three radars will be transportable, scanning, polarimetric and Doppler.

Development of a useful 3D cloud Value Added Product (VAP) similar to the existing ARSCL but on a regular 3D grid.

Development of an "AVA Simulator.” Patterned after the well-known ISCCP Simulator, the AVA Simulator will perform forward simulations of radar observables, using as input LES model and cloudresolving model outputs of cloud properties together with the characteristics of the AVA radars. The results will be used to develop and optimize volumetric radar scanning strategies, develop and evaluate inverse retrieval techniques, and develop prototype 3D ARSCL-like VAPs for the ARM community.

A collaborative effort with the Center for Interdisciplinary Remotely-Piloted Aircraft Studies (CIRPAS) to deploy the CIRPAS 9.4-GHz phased-array radar at the ARM SGP site every year for 1-2 months of continuous observations.

STATUS - Eugene Clothiaux will present the proposal to the ARM Science Team Executive Committee (STEC) at their August meeting.

\subsection{Portable Raman Lidar}

STATUS - Leosphere http://www.lidar.fr/ offers a portable MPL-type lidar that can be augmented with Raman capability. Raymetrics http://www.raymetrics.gr/(sold by Kipp \& Zonen) also offers a Raman Lidar. Both concerns have been invited to deploy their systems at SGP for comparison with the SGP Raman Lidar and MPL. Leosphere is planning to deploy a lidar at the SGP in late October. 


\subsection{Absolute Scanning Radiometer}

To provide an absolute IR flux reference, which could be used to calibrate the Eppley PIRs, Ells Dutton has suggested that ARM develop an Absolute Scanning Radiometer (ASR). This instrument would be functionally equivalent to an ASR developed by Rolf Philipona for the WMO. This instrument would not be used for routine data acquisition, but instead would provide a calibration reference. As such it would participate in WMO inter-comparisons at Davos, Switzerland every five years. Although an Small Business Innovation Research (SBIR) solicitation for an ASR was issued circa 2000, no successful proposals were received.

STATUS - Ells Dutton, Tom Stoffel, and Joe Michalsky are planning to develop a specification so that ACRF may send out a request for proposals to identify interest and cost for such an instrument.

\subsection{High-Resolution Oxygen A-Band and Water-Band Spectrometer}

Qilong Min has submitted a proposal to build an A-band spectrometer for ARM following his presentation to the Cloud Properties working group in October 2004 on this topic. The 3-year proposal and budget were sent out for technical reviews. The technical reviews, along with the proposal and budget, were then provided to the STEC. The STEC directed Qilong to present his plan and budget to the Cloud Properties working group at their November 2005 meeting for prioritization. Qilong presented a revised work plan (water-band/cloud phase components removed) and has submitted a revised budget.

\subsection{Rotating Shadowband Spectrometer Overhaul}

Peter Kiedron has demonstrated that the RSS built by Yankee Environmental System is capable of providing valuable measurements of direct, diffuse, and global spectral irradiance. Peter has also identified problems with the RSS that affect the stability of its calibration and the linearity of its response. Peter has recommended that the RSS be removed from service and sent to him at SUNY-Albany for a complete overhaul.

\subsection{Narrow Field of View Radiometer for Atmospheric Radiatin Measurement Program Mobile Facility}

The 2-channel Narrow Field of View (NFOV) that was deployed with the AMF at Pt. Reyes has been redeployed at SGP. A second 2-ch NFOV has been suggested for the AMF, although not for the Niger deployment.

STATUS - Science Team members (Alexander Marshak and others) have decided that this is no longer necessary. Due to the deployment of the new SWS at SGP, the 2-channel NFOV at SGP can be deployed with the AMF in 2007. 


\subsection{Add 1.6 $\mu \mathrm{m}$ Channel to Multi-Filter Rotating Shadowband Radiometer and Narrow Field of View}

Alexander Marshak has recommended that ARM support the development of a NFOV radiometer at $1.6 \mu \mathrm{m}$ to permit the retrieval of droplet size distribution. Andy Lacis and colleagues have suggested a $1.6 \mu \mathrm{m}$ channel be substituted for the unfiltered (broadband) channel in the MFRSR. A cursory examination of Perkin-Elmer's web pages reveals Indium-Galium-Arsinide (InGaAs) detectors are available that operate in this spectral region. This would require a development effort.

STATUS - Two InGaAs detectors and two $1.6 \mu \mathrm{m}$ filters have been purchased to determine the feasibility of implementing them in the MFRSR and/or NFOV. In the MFRSR this filter-detector would replace the unfiltered (broadband) channel. Because the unfiltered channel is now being used in a broadband radiometer best estimate VAP for quality checking purposes, only a limited number of MFRSRs would be modified to accept a $1.6 \mu \mathrm{m}$ channel.

\subsection{Aerosol Particle Sizing Spectrometer to Replace Optical Particle Counter at Southern Great Plains}

John Ogren has suggested replacing the aging Optical Particle Counter (OPC) included in the SGP AOS with a new Aerosol Particle Sizing Spectrometer (APS) to be integrated into the existing TDMA.

\subsection{Future Microwave Radiometers}

The 2-channel MWRs range between 6-13 years old. They are no longer being manufactured; Radiometrics has replaced them with an instrument that sequentially tunes to 5 frequencies in the 22$30 \mathrm{GHz}$ range. Although Radiometrics continues to support the MWRs, it is useful to begin considering replacements for these instruments. Although $5 \mathrm{~K}$-band channels may provide more robust retrievals than 2 channels, RPG offers a comparably priced 3-channel radiometer (23.8, 31.4, 90.0 GHz) that could also be considered because it increases the sensitivity to thin liquid water clouds. It is also desirable to acquire a final, "production" version of the $183 \mathrm{GHz}$ microwave radiometer developed by ProSensing under a U.S. Department of Energy (DOE) SBIR Phase II award and deployed at Barrow since April 2005.

\subsection{Modified Muti-Filter Rotating Shadowband Radiometer for Liquid Water Path}

Qilong Min has proposed to modify the existing MFRSRs to permit him to retrieve liquid water path. Software modifications would be required to position the shadow band at several additional angles near the solar disk; modifications to the shadow band would be needed to either narrow it or increase its distance from the diffuser. A narrower diffuser (and modification to the sensor head) and an improved stepper motor and motor controller have also been proposed. A first phase might utilize a Rotating Shadowband Radiometer loaned to Min from Brookhaven National Laboratory. 


\subsection{Infrared Thermometers for the Southern Great Plains Extended Facility Sites}

John Ogren has suggested replacing the aging OPC included in the SGP AOS with a new APS to be integrated into the existing TDMA. 


\section{Small Business Innovation Research}

\subsection{Oxygen A-Band Spectrometer (FY 2005)}

Based on recommendations from the 2004 ARM Science Team meeting breakout session on photon path length measurements, a subtopic requesting the development of an A-band spectrometer was included under the Atmospheric Technology.

In May 2005 Dr. Fedor Dimov of Physical Optics Corporation was awarded a Phase I grant for A-band spectrometer development.

STATUS - Kevin Yu and Fedor Dimov have submitted a Phase II proposal.

\subsection{Eye-Safe Ultraviolet Backscatter Lidar for Detection of Sub-visual Cirrus (FY 2006)}

Based on recommendations from the 2004 Cloud Properties working group meeting, this subtopic was substituted for the A-band spectrometer subtopic. Connor Flynn is the technical contact.

STATUS - Phase I funding was awarded to Aculight Corporation: "Eye-Safe ultraviolet Backscatter Lidar for Detection of SubVisual Cirrus" and to Physical Sciences, Inc.: "Field-Worthy ultraviolet Backscatter Lidar for Cirrus Studies.”

\subsection{Instrumentation for Remotely Sensing Aerosol Optical Properties - Aerosol Phase Function (FY 2006)}

Based on recommendations from the Aerosol working group, this subtopic was added to the aerosol measurements subtopic. Frank Evans is the technical contact.

STATUS - Phase I funding was awarded to Aerodyne Research, Inc.: “CAPS-Based Particle Single Scattering Albedo Monitor.”

\subsection{Unmanned Aerospace Vehicle-Suitable Cloud Radar (FY 2006)}

STATUS - Phase I funding was awarded to ProSensing, Inc: "High-Power, Pod-Mounted W-band Cloud Radar for Unmanned Aerospace Vehicles (UAV).”

\subsection{Radiometer Radiosonde (FY 2006 National Science Foundation Solicitation)}

The objective is to obtain a radiosonde with an onboard radiometer suitable for accounting for the radiative heating of the temperature sensor in the upper atmosphere. This is potentially interesting to ARM as a means for directly measuring the heating rate profile. Global Aerospace was awarded Phase I funding: 
http://www.nsf.gov/awardsearch/showAward.do?AwardNumber=0539943

STATUS - Matt Heun of Global Aerospace inquired about ARM's requirements for heating rate profile measurements. The BBHRP focus group provided their requirements to Matt. Matt and his colleagues have determined that, within the context of their current National Science Foundation SBIR project, they cannot control the tilt of the radiometers sufficiently to achieve the accuracy requirements provided by ARM; however, this could become the subject of a future DOE SBIR subtopic. Global Aerospace representatives have been invited to attend the ARM Radiative Heating Profile Workshop being organized by Warren Wiscombe.

\subsection{In-situ Measurement of Cloud Properties with Large Sample Volumes (FY 2007)}

Warren Wiscombe contributed the following sub-topic and will be the technical contact.

The DOE ARM Program was formed to study the climatic effects of clouds. These effects, particularly how clouds respond to climate change (the so-called "cloud feedback" problem), are large yet poorly understood from both a measurement and modeling point of view (cf. Stephens 2005). Currently, there is a huge gap in spatial scale between in-situ measurements of cloud properties, typically from aircraft and balloons whose instruments have sample volumes on the order of cubic centimeters, and remote sensing retrievals of cloud properties, which have sample volumes ranging from tens of cubic meters (radar and lidar) to thousands of cubic meters (satellites). Most acute is the fact that in-situ measurements at a particular point give no information on the vertical distribution above and below that point, while active remote sensing retrievals typically give instantaneous vertically-resolved information. Since clouds are inhomogeneous down to centimeter scales, there is a complete lack of comparability between in-situ measurements and remote retrievals; simple assumptions of homogeneity to scale up the in-situ measurements are certainly false. Clouds also evolve considerably in the course of a minute, and thus methods, which are slow in time (such as a balloon ascending, or an aircraft ascending or descending) fail to capture the instantaneous state which remote sensing sees. Thus, there is a great need for in-situ measurements which have fast vertical reach and much larger sample volumes, ranging from cubic meters to hundreds of cubic meters, in order to allow meaningful comparisons with surface and satellite retrievals of cloud properties. Without confidence in those surface and satellite retrievals, which are our only way to extend our reach to the whole planet, it is impossible to make progression key global change issues concerning cloud feedbacks on global warming.

Therefore, grant applications are sought to develop instruments to measure cloud properties in-situ, for scales ranging from cubic meters to hundreds of cubic meters, with particular emphasis on fast vertical profiling above and below the in-situ platform. (The platform need not be a traditional aircraft or balloon; instruments for small UAVs, kites, gliders, and tethered balloons will also be considered.) An example of such an instrument can be seen in Evans, et al. (2003). Measurements of the following cloud properties are particularly wanted, in order of decreasing priority for cloud-climate applications: (a) extinction coefficient at one or more wavelengths in the solar spectrum away from strong water vapor absorption bands; (b) total water content (liquid plus ice); (c) liquid and ice water content separately; (d) effective radius, defined as the ratio of the $3^{\text {rd }}$ to the $2^{\text {nd }}$ moment of the drop size distribution; (e) absorption coefficient or single-scattering albedo at one or more wavelengths in the solar spectrum away from strong 
water vapor absorption bands; (f) the scattering phase function for ice clouds; (g) the drizzle and precipitation fraction of the total condensed water content; (h) the supersaturation; (i) the dispersion, a measure of the width of the drop size distribution.

Stephens, G. 2005. “Cloud feedbacks in the climate system: A critical review.” Journal of Climate 18:237-273.

Evans, K.F. 2003. "In situ cloud sensing with multiple scattering lidar: Simulations anddemonstration.” Journal of Atmospheric and Oceanic Technology 20:1505-1522. 